\title{
Bio-Inspired Mineral Growth on Porous Spherulitic Textured Poly(L-lactic acid)/Bioactive Glass Composite Scaffolds**
}

\author{
By Satyabrata Ghosh, Rui L. Reis and João F. Mano*
}

In tissue engineering approach, a porous 3D biodegradable polymeric scaffold plays an important role in cell attachment, proliferation, differentiation and formation of new tissue. ${ }^{[1]}$ The commonly accepted materials for tissue engineering applications are synthetic biodegradable polymers like poly(L-lactic acid) / PLLA, poly(D,L-lactic acid)/ PDLLA, poly(glycolic acid)/PGA and their co-polymers/ PLGA. ${ }^{[2]}$ The implantation of an artificial material into bone defects is frequently encapsulated by a fibrous tissue, leading to the isolation of implants from the surrounding tissue. Bioactive ceramics such as hydroxyapatite and bioactive glasses reacts with body fluid and forms a biologically active hydroxyapatite layer, which provides the interfacial bonding sites of host tissues. ${ }^{[3-5]}$ On one hand, the ceramics and glasses are brittle, and thus restrict its usages as implants. On the other hand, the polymers are ductile. The composites of the polymers with bioactive glass would allow processing the composites by conventional thermoplastics processing technique and could improve the fracture toughness as well as induce bioactivity in the polymer-ceramics composite scaffolds. $^{[6]}$

Shikinami and Okuno $^{[7]}$ reported that the commercial PLLA/hydroxyapatite composite devices like miniplates and miniscrews can be conveniently fabricated using melt based

[*] Dr. S. Ghosh, Prof. R. L. Reis, Prof. J. F. Mano

3B's Research Group - Biomaterials

Biodegradables and Biomimetics

Department of Polymer Engineering

University of Minho

4710-057 Braga, Portugal

and

IBB-Institute for Biotechnology and Bioengineering

PT Government Associated Laboratory

Braga, Portugal

E-mail:jmano@dep.uminho.pt

[**] Financial support for this work was provided by FCT, through the POCTI and FEDER programmes, and projects POCTI/ FIS/61621/2004 and PTDC/QUI/69263/2006. S. Ghosh thanks FCT for awarding the PhD grant, SFRH/BD/12657/2003. This work was also partially supported by the European Union funded STREP Project HIPPOCRATES(NMP3-CT-2003505758). technique. The fabrication of porous scaffolds from the polymer melt is the most convenient method, as it allows the fast production of scaffolds of different shapes and sizes in an efficient way. The fabrication technique involves melting of a thermoplastic/ceramics/salt mixture into a compact disc followed by leaching of salt in water. In this organic solvent free fabrication technique, the void fraction and pore size in a scaffold could be independently controlled by the fraction and size of pre-seeded salt particles. The versatility of this technique allows preparing porous 3D mono-layered and bilayered bioactive polymer-ceramics composite scaffolds. ${ }^{[8,9]}$

The acidic degradation products of polyester based polymers PLLA, PDLLA, PGA and PLGA are a common concern in some tissue engineering applications. ${ }^{[7,10]}$ Moreover, Day et al. ${ }^{[11]}$ reported that the biodegradable polymer coated with bioglass reduced the rate of cell proliferation, that could be related to the direct exposure of cells to alkaline dissolution products of bioactive glass. The melt compounding process allows embedding the bioactive glass into thermoplastic matrix. In contact with body fluid, the composites could exhibit acid-base neutralization through the acidic moieties released from degradation of polyester and basic ions released from the hydrolysis of bioactive glass. ${ }^{[12]}$

It has been shown that texture can strongly influence the adhesion, orientation and proliferation of cells onto the surface of biomaterials. ${ }^{[13]}$ Many technological procedures have been employed to induce controlled patterning on flat polymeric surfaces, but most of them cannot be transferred towards complex geometries such as for the modifying the internal pores in 3D scaffolds. We have previously shown that it is possible to imprint micrometer level textures throughout the scaffolds by melt compounding PLLA/polyethylene oxide (PEO) blend, quenching followed by leaching of PEO in water. ${ }^{[8]}$ The objective of this work is to verify how the texture in 3D porous PLLA/Bioglass ${ }^{\circledR}$ composite scaffolds may influence the precipitation of apatite in vitro.

\section{Experimental}

\section{Materials}

PLLA used in this study had L-lactide content of $99.6 \%$, $M_{n}=69.000$ and polydispersity of 1.73 and obtained from Cargill Dow LLC, USA. ${ }^{[14]}$ The PEO selected for this study was Polyox WSR N-10 and $M_{n}=100,000$ from Dow Chemical Company, USA. The bioactive glass used in this study was 45S5 Bioglass ${ }^{\circledR}$, from Novamin Technology Inc. USA, and had 
wt \% composition of $45 \% \mathrm{SiO}_{2}, 24.5 \% \mathrm{CaO}, 24.5 \% \mathrm{Na}_{2} \mathrm{O}$ and $6.0 \% \mathrm{P}_{2} \mathrm{O}_{5}$. The size of the bioactive glass particles was 38 to $63 \mu \mathrm{m}$. The size of the $\mathrm{NaCl}$ particles was 250 to $500 \mu \mathrm{m}$.

\section{Scaffold Fabrication}

The fabrication procedure of the scaffolds using compression molding and porogen leaching has been described in detail elsewhere ${ }^{[8]}$ Briefly, the PLLA was cryogenically milled and mixed with PEO. The sieved $\mathrm{NaCl}$ particles and Bioglass ${ }^{\circledR}$ particles were mixed with the powdered polymer. The added wt $\%$ percent composition of PLLA/Bioglass ${ }^{\circledR}$ (s-PLLA/ Bioglass ${ }^{\circledR}$ ) compact disk was PLLA: Bioglass ${ }^{\circledR}$ : $\mathrm{NaCl}=21: 9: 70$. The porous 3D composite scaffolds were obtained by leaching of $\mathrm{NaCl}$ particles in water and the wt \% composition of PLLA: Bioglass ${ }^{\circledR}$ in the porous composite scaffold was 78: 22.

\section{Fabrication of Textured Scaffolds}

A number of factors like the material, surface chemistry, polymer/bioactive ceramics compositions, temperature plays decisive roles in the precipitation of calcium phosphate from simulated body fluid. ${ }^{[15-17]}$ In order to investigate the role of surface texture on the biomineralization process, a spherulitic-like pattern was produced on porous PLLA-Bioglass ${ }^{\circledR}$ composite scaffolds. The added wt \% composition of the PLLA/ Bioglass ${ }^{\circledR}$ compact disk (t-PLLA/ Bioglass ${ }^{\circledR}$ ) was PLLA : PEO : Bioglass $^{\circledR}: \mathrm{NaCl}=20.6: 1.8: 8.9: 68.7$. The wt $\%$ composition of PLLA: Bioglass ${ }^{\circledR}$ in the textured, porous composite scaffold was 79.9: 20.1. Figure 1 shows the schematic of preparing a textured PLLA surface. PLLA and PEO are miscible in molten state and form a homogeneous phase. ${ }^{[18]}$ The miscibility was kept by quenching the melt to $0^{\circ} \mathrm{C}$. Upon immediate immersion into water, the homogeneous PLLA/PEO phase absorbs water owing to the presence hydrophilic PEO component, and the absorbed water could plasticize the homogeneous blend. The highly crystallizable PEO crystallizes in spherulitic shape from homogeneous blend and phase separates. During crystallization of PEO, the PLLA component is entrapped within the spherulitic structure. The dissolution of PEO creates the patterned spherulitic texture on the PLLA surface.

The miscibility or single phase ordering of a polymer blend depends on the intermolecular interaction between the polymers in molten state. The intermolecular forces are dipolar, van der Waals and hydrogen bonding, and the summation of these forces is termed as solubility parameter. The close solubility parameters of PLLA and PEO (10.1 and $\left.9.9 \pm 1\left(\mathrm{cal}^{\mathrm{cm}} \mathrm{cm}^{-3}\right)^{1 / 2}\right)$ indicate the thermodynamic miscibility of PLLA/PEO blend. ${ }^{[19]}$ The crystallized PEO is thermodynamically more stable than amorphous PEO in homogeneous PLLA/PEO phase, and the water temperature $\left(37^{\circ} \mathrm{C}\right)$ in between $T_{\mathrm{g}}\left(-54^{\circ} \mathrm{C}\right)$ and $T_{\mathrm{m}}\left(58^{\circ} \mathrm{C}\right)$ of PEO is favourable for crystallization. The driving force for phase separation is the crystallization PEO from homogeneous PLLA/PEO phase.
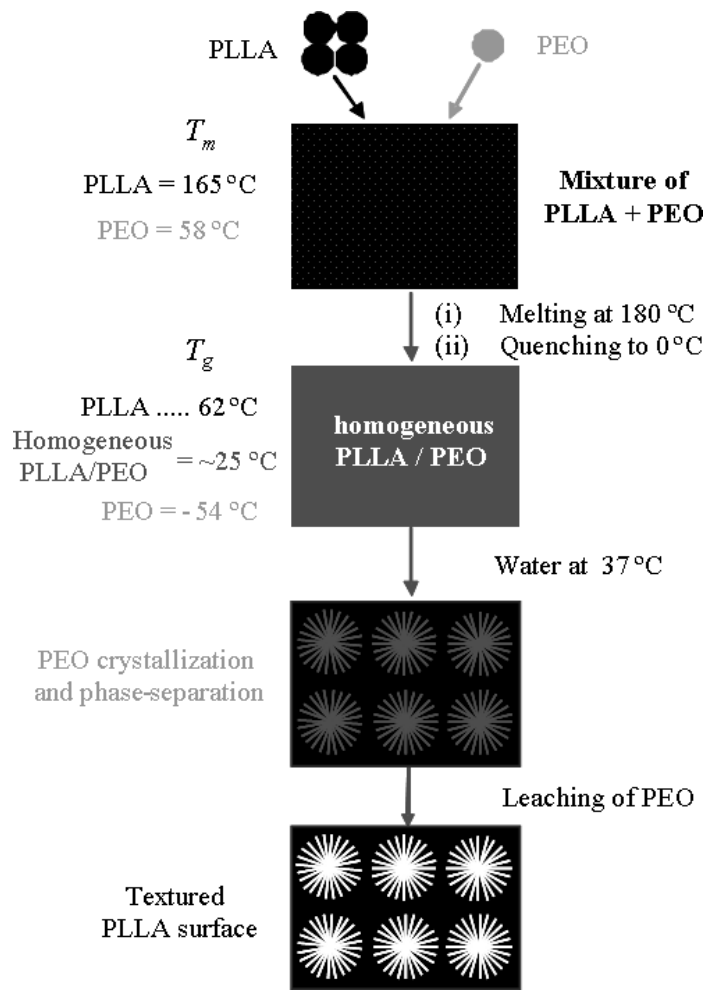

Fig. 1. Schematic showing the different stages of the process for fabricating micrometer sized spherulitic textures on macroporous $3 D$ polymeric scaffold surface. A compact $3 \mathrm{D}$ disc is prepared by melting a PLLA/PEO/Bioglass/NaCl mixture where $\mathrm{NaCl}$ and Bioglass particles are dispersed. Upon immediate immersion in water at $37^{\circ} \mathrm{C}$, the highly crystallizable PEO phase separates from homogeneous PLLA/PEO blend with the crystallization of PEO. The phase separated PEO dissolves and leaches out leaving behind 3D spherulitic pattern on PLLA.

This miscibility in the molten state followed by a phase separation in the solid state through crystallization is commonly observed in miscible amorphous-crystalline polymer blends. ${ }^{[18]}$

\section{Biomineralization Experiment}

The in vitro apatite-forming capability (bioactivity) of the porous 3D composite scaffolds was assessed in a simulated body fluid (SBF) with the ion composition similar to human blood plasma. ${ }^{[20]}$ One liter SBF was prepared with the addition of $8.036 \mathrm{~g} \mathrm{NaCl}, 0.352 \mathrm{gNaHCO}_{3}, 0.225 \mathrm{~g} \mathrm{KCl}, 0.230 \mathrm{~g}$ $\mathrm{K}_{2} \mathrm{HPO}_{4} \cdot 3 \mathrm{H}_{2} \mathrm{O}, 0.311 \mathrm{~g} \mathrm{MgCl}_{2} \cdot 6 \mathrm{H}_{2} \mathrm{O}, 40 \mathrm{ml} 1 \mathrm{M} \mathrm{HCl}, 0.293 \mathrm{~g}$ $\mathrm{CaCl}_{2}, 0.072 \mathrm{~g} \mathrm{Na}_{2} \mathrm{SO}_{4}$ in one liter of distilled water. In addition to that, $6.063 \mathrm{~g}$ TRIS [tris(hydroxymethyl)aminomethane] was added with continuous stirring while $\mathrm{pH}$ was adjusted to $\mathrm{pH} 7.4$ with the addition of either $1 \mathrm{M} \mathrm{HCl}$ or $1 \mathrm{M} \mathrm{NaOH}$. Prior to incubating the porous scaffolds in SBF, a series of depressurization and repressurization cycles were performed in solution to remove the trapped air and to make wet the internal surface of the pores. Three scaffolds were immersed in each polyethylene test tubes containing $50 \mathrm{ml} \mathrm{SBF}$ at $37^{\circ} \mathrm{C}$ for 0,1 and 3 days. After the predetermined time periods, the samples were taken out of the test tubes, rinsed in deionised water $(\mathrm{pH}=5.35)$ to remove the inorganic ions, patted dry on 
adsorbent paper and dried at $40{ }^{\circ} \mathrm{C}$ under vacuum for 24 hrs. $^{[9]}$

Characterization of mineralized scaffolds: The mineralized scaffolds were characterized in an X-ray diffractometer (XRD) (Rigaku Geigerflex D/Mac, $\mathrm{C}$ series diffractometer with $\mathrm{Cu} \mathrm{K}_{a}$ radiation, $\lambda=1.5406 A$ ). The scan range was $2 \theta=3.025$ to $59.975^{\circ}$ with step size of $0.05^{\circ}$. The PLLA and Bioglass ${ }^{\circledR}$ distribution in the scaffold was assessed by X-ray microcomputed tomography (SkyScan1072, Belgium), $\mu-\mathrm{CT}$ analysis. The apatite formation in the scaffolds was assessed by scanning electron microscopy (Leica Cambridge S-360, UK) at $15 \mathrm{kV}$.

\section{Results and Discussion}

Biomimetic Apatite Formation on Non-Textured and Textured 3D Scaffolds

The $\mu$-CT image in Figure 2(a) shows the representative distribution of PLLA, Bioglass ${ }^{\circledR}$ and pores of a porous PLLA/Bioglass ${ }^{\circledR}$ composite scaffold (s-PLLA/bioglass), prepared by compression molding a mixture of PLLA/Bioglass ${ }^{\circledR} / \mathrm{NaCl}$ followed by dissolution of $\mathrm{NaCl}$. The higher magnification SEM micrograph in Figure 2(b) shows the non-textured surface of the scaffold. The s-PLLA/bioactive glass composite scaffolds were immersed in SBF at pH 7.4 for 1 and 3 days. Figure 2(c) shows that the apatite nucleates, grows as spheroids and aggregates in a typical cauliflower-like morphology with needle-like growth along c-axis on scaffold surface. The presence of XRD peaks at $2 \theta=26$ and $34-36^{\circ}$ confirms that apatite formation takes place after immersion into SBF. ${ }^{[21,22]}$ The thickness of the apatite coating was increasing with increasing immersion time (Fig. 2(d)). No apatite-like precipitation was observed on pure PLLA scaffolds. The dissolution of bioactive glass in SBF increases the ionic concentration and apatite formation takes place due to the solution supersaturation with respect to activity product of hydroxyapatite (HA). The apatite precipitation continues with progressive dissolution of bioglass and ceases when the solution supersaturation is reduced below the activity product of HA. Moreover, Boccaccini et al. showed that the presence $\mathrm{TiO}_{2}$ nanoparticles in PDLLA/bioactive glass composite scaffolds increased the amount of apatite precipitation. ${ }^{[23]}$

The SEM micrograph in Figure 3(a) shows the textured surface of porous PLLA/Bioglass ${ }^{\circledR}$ composite scaffolds (t-PLLA/bioglass) where the spherulitic pattern was produced from the PLLA/ $\mathrm{PEO} /$ Bioglass ${ }^{\circledR} / \mathrm{NaCl}$ mixture following the sequence of the schematic in Figure 1. The t-PLLA/ bioglass composite scaffolds were immersed into $\mathrm{SBF}$ at $\mathrm{pH}$ 7.4. Figure 3(b) shows the mineral layer formed on the textured composite scaffolds after

(e) one day in SBF. Figures 3(c) and 3(d) shows the mineral layer after 3 days in SBF. The inorganic coating formed on textured scaffolds is completely different from the one observed in the non-textured scaffolds (Figs. 2(c) and 2(d)). The sizes of the oriented crystals are between $30-100 \mu \mathrm{m}$ in length, $1-10 \mu \mathrm{m}$ in breadth and thickness of less than $1 \mu \mathrm{m}$. The crystals grow along the surfaces and, in certain areas; the crystal growth front ruptures the polymeric matrix and grows along the surface - see Figure 3(c).

This blade or plate-like morphology is the characteristics of octacalcium phosphate (OCP) crystals. ${ }^{[24]}$ It is difficult to identify the presence of OCP peaks from the XRD spectra in Figure 3(e) because of the close structural similarity between OCP and HA. ${ }^{[2]}$ The transformation of OCP to thermodynamically stable HA always keeps a certain amount mixed phase instead of pure OCP. The peaks corresponding to OCP at $2 \theta=26,32,34-36^{\circ}$ are not well-resolved because of the
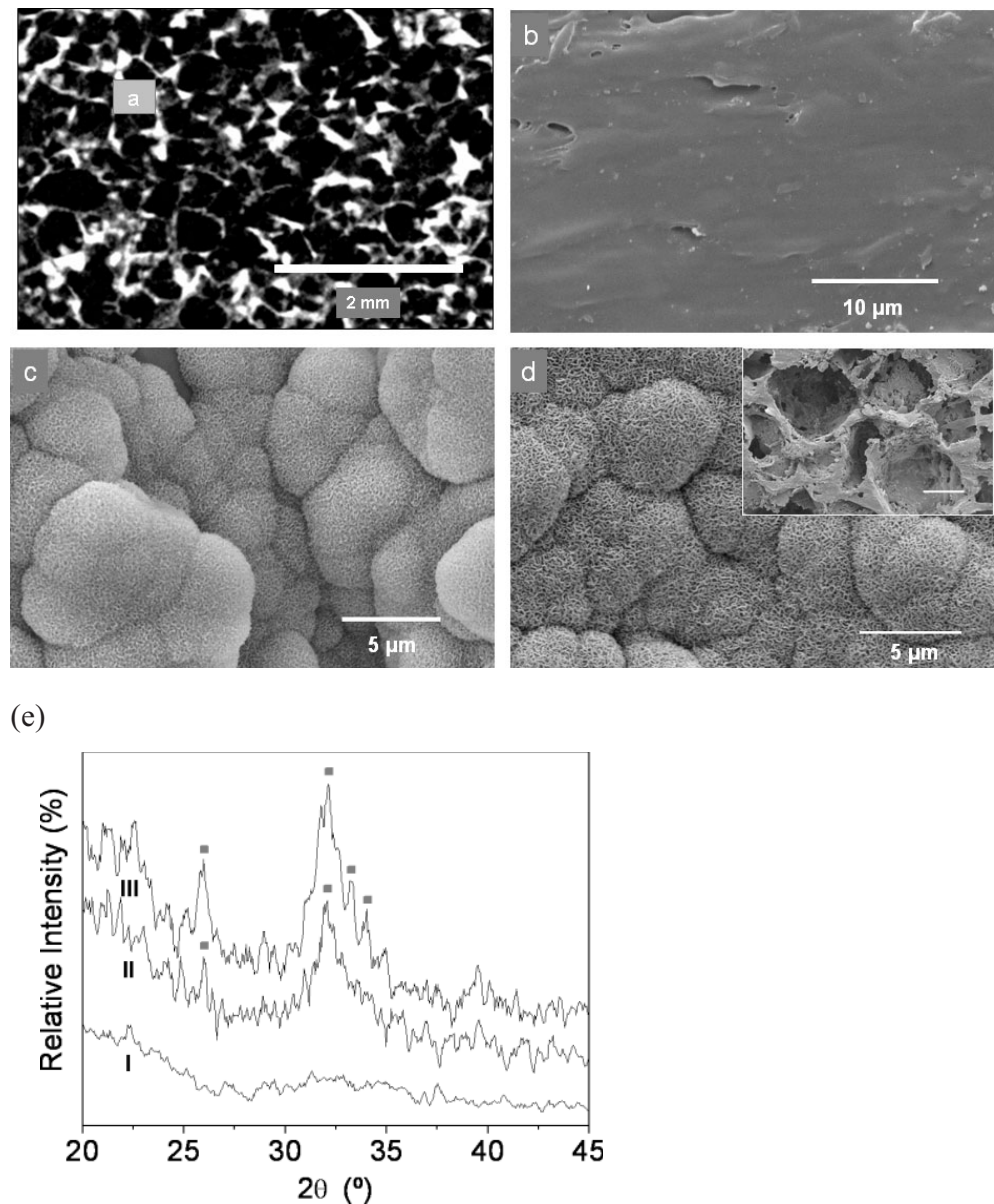

Fig. 2. (a) A representative $\mu-C T$ image showing the distribution of PLLA, Bioglass ${ }^{\circledR}$ and pores of a porous three-dimensional PLLA/Bioglass composite scaffolds: PLLA in light-grey shade, Bioglass in white shade and the pores in black shade; (b) representative SEM image showing the smooth surface of a porous PLLA/Bioglass ${ }^{\circledR}$ scaffold prepared by compression molding of PLLA/Bioglass/NaCl fol lowed by dissolution of porogen, (c) porous s-PLLA/Bioglass composite scaffolds after one day in $S B F$; (d) after three days in SBF, the inset is in lower magnification with scale bar $=200 \mu \mathrm{m}$; (e) Xray diffraction spectra of porous s-PLLA/Bioglass composite scaffolds: (I) before putting into SBF, (II) after one day incubation in SBF, and (III) after three days in SBF. Peaks associated with hydroxyapatite are denoted by 

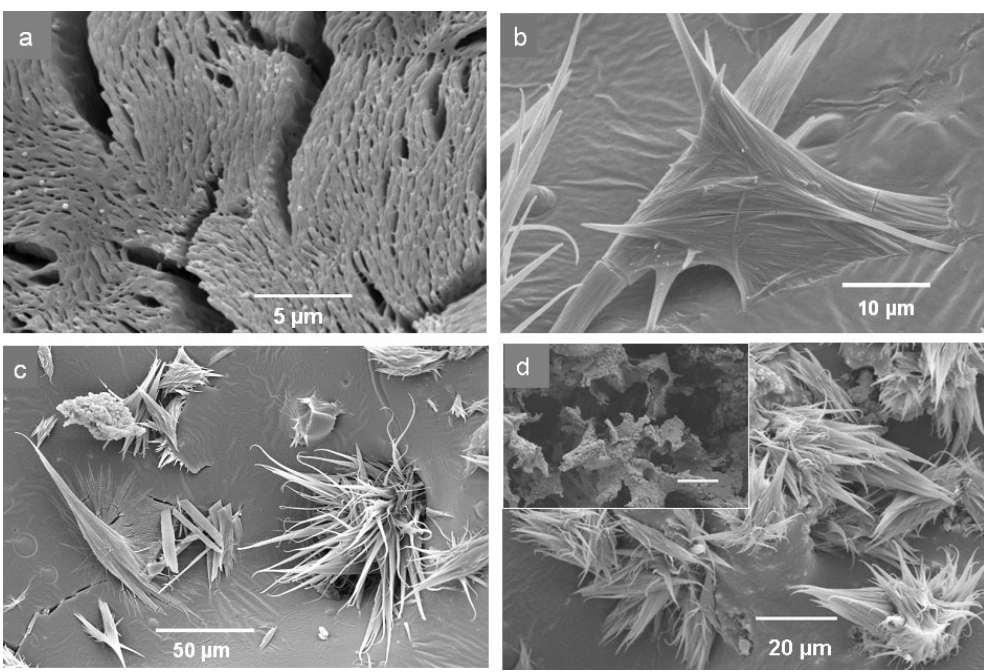

(e)

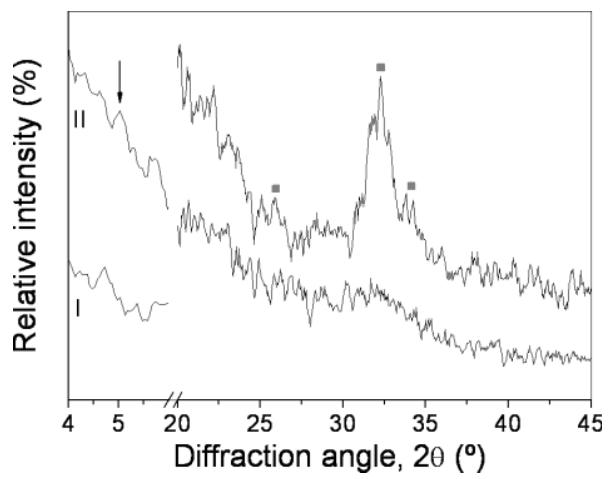

Fig. 3. (a) Representative SEM image showing the spherulitic patterned surface of a porous PLLA scaffold prepared from compression molding of PLLA/PEO/NaCl/Bioglass ${ }^{\circledR}$ followed by dissolution of $\mathrm{PEO}$ and $\mathrm{NaCl}$ in water, (b) t-PLLA/Bioglass composite scaffolds after one day in $\mathrm{SBF} ;(c, d)$ after three days in SBF and the inset in Figure 3(d) shows the scaffolds in lower magnification with scale bar $=200 \mu \mathrm{m}$; and (e) X-ray diffraction spectra of porous t-PLLA/Bioglass composite scaffolds: (I) before putting into $S B F$, and (II) after one day incubation in $S B F$, Peaks associated with OCP are denoted by, and OCP/HA mixed peaks by

presence of mixed phase of OCP and HA. The co-existence of $\mathrm{OCP}$ and $\mathrm{HA}$ is also common in biological apatites.

Three different types of Ca-P namely DCPD, dicalcium phosphate $\left[\mathrm{CaHPO}_{4} 2 \mathrm{H}_{2} \mathrm{O}\right]$, octacalcium OCP, phosphate $\left[\mathrm{Ca}_{8}\left(\mathrm{HPO}_{4}\right)_{2}\left(\mathrm{PO}_{4}\right)_{4} 5 \mathrm{H}_{2} \mathrm{O}\right]$ and $\mathrm{HA}$, hydroxyapatite $\left[\mathrm{Ca}_{10}\right.$ $\left(\mathrm{PO}_{4}\right)_{6}(\mathrm{OH})_{2}$ ] could precipitate from SBF. The solubility products of DCPD, OCP and HA are $10^{-6.62}, 10^{-36.48}$ and $2.35 \times 10^{-59}$ respectively. ${ }^{[24]}$ Although, OCP and DCPD have been recognized as precursors of HA, DCPD is thermodynamically unstable at physiological $\mathrm{pH}$. Therefore, only OCP and HA could precipitate from SBF. The nucleation rate of OCP is 10 orders higher than HA at physiological $\mathrm{pH}$ of 7.4. ${ }^{[25]}$

The origin for the formation of OCP prior to HA on micrometer-sized textured surface of PLLA/Bioglass ${ }^{\circledR}$ composite scaffolds from SBF at $\mathrm{pH}=7.4$ is not yet clear. The kinetically favored OCP could precipitate by lowering of activation energy barrier, which could have facilitated by the textured surface. The activation energy barrier may decrease through interfacial recognition of inorganic nuclei to organic surface. ${ }^{[2]}$ There could be some geometric and structural match between inorganic phase and spherulitic surface of PLLA that facilitated the OCP nucleation. Mao et al. $^{[26]}$ reported the formation of OCP on textured titanium surface from a supersaturated solution of HA, where the growth of OCP crystals was not parallel to the surface.

The OCP crystals of 10 to 100 micrometer are in contrast with scale of nanometer sized crystal nucleates from solution. ${ }^{[27]}$ Mann and Colfen ${ }^{[28]}$ proposed that the crystal nucleation and the mesophase transformation to higher ordered structures may take place in a gel-like interfacial layer. In the present study, the mesophase transformation of OCP could have occurred in colloidal silicic acid or oligomeric silicic acid, which typically forms a gel-like intermediate from the dissolution of bioactive glass in SBF. ${ }^{[2]}$ From biological point of view, this result could be relevant as OCP is a precursor of bone, integrates better with the host tissue and stronger osteogenic potential than HA. ${ }^{[30]}$

\section{Conclusions}

A new technique for the fabrication of biodegradable, porous, three-dimensional polymer/bioglass composite scaffolds was developed using the most straightforward compression molding technique and porogen leaching process. The micrometer scale microporous textured surface was produced through crystallization of PEO from a homogeneous blend and followed by porogen leaching. The textured surface was able to preferentially induce the nucleation and growth of OCP as compared with smooth surfaces precipitates the typical apatite upon immersion in SBF. Therefore, it is suggested that the texture of the surface may have an influence in the nature and morphology of Ca-P precipitation. However, more tests would be required to validate this hypothesis and to clearly understand the underlying mechanism of this phenomenon. This synthetic process of producing OCP on porous 3D polymer surface similar to natural biomineralization may open new opportunities in tissue engineering application. This novel technique of preparing textured, porous 3D polymer/ceramic composite scaffolds without any external template may have direct biological relevance and broad implication in new materials synthesis.

Received: December 26, 2007

Final version: May 22, 2008

Published online: July 14, 2008

[1] D. W. Hutmacher, Biomaterials 2000, 21, 2529.

[2] J. C. Middleton, A. J. Tipton, Biomaterials 2000, 21, 2335.

[3] T. Kokubo, H. M. Kim, M. Kawashita, Biomaterials 2003, $24,2161$. 
[4] J. D. De Bruijn, C. A. Van Blitterswijk, J. E. Davies, J. Biomed. Mater. Res. 1995, 29, 89.

[5] A. El-Ghannam, P. Ducheyne, I. M. Shapiro, J. Orthop. Res. 1999, 17, 340.

[6] J. A. Juhasz, S. M. Best, R. Brooks, M. Kawashita, N. Miyata, T. Kokubo, T. Nakamura, W. Bonfield, Biomaterials 2004, 25, 949.

[7] Y. Shikinami, M. Okuno, Biomaterials 1999, 20, 859.

[8] S. Ghosh, J. C. Viana, R. L. Reis, J. F. Mano, J. Mater. Sci.- Mater. Med. 2007, 18, 185.

[9] S. Ghosh, J. C. Viana, R. L. Reis, J. F. Mano, Mater. Sci. Eng. C 2008, 28, 80.

[10] C. M. Agrawal, K. A. Athanasiou, J. Biomed. Mater. Res. 1997, 38, 105.

[11] R. M. Day, V. Maquet, A. R. Boccaccini, R. Jerome, A. Forbes, J. Biomed. Mater. Res. A 2005, 75, 778.

[12] H. Li, J. Chang, Compos Sci. Technol. 2005, 65, 2226.

[13] A. F. von Recum, T. G. van Kooten, J. Biomater. Sci., Polym. Ed. 1995, 7, 181.

[14] S. Ghosh, J. C. Viana, R. L. Reis, J. F. Mano, Polym. Eng. Sci. 2007, 47, 1141.

[15] A. L. Oliveira, J. F. Mano, R. L. Reis, Curr. Opin. Solid State Mater.Sci. 2003, 7, 309.

[16] K. Rezwan, Q. Z. Chen, J. J. Blaker, A. R. Boccaccini, Biomaterials 2006, 27, 3413.
[17] J. Shi, N. M. Alves, J. F. Mano, Adv. Funct. Mater. 2007, 17, 3312.

[18] A. J. Nijenhuis, E. Colstee, D. W. Grijpma, A. J. Pennings, Polym. 1996, 37, 5849.

[19] E. Meaurio, E. Zuza, J. R. Sarasua, Macromolecules 2005, $38,1207$.

[20] T. Kokubo, H. Takadama, Biomaterials 2006, 27, 2907.

[21] V. M. Rusu, C.-H. Ng, M. Wilke, B. Tiersch, P. Fratzl, M. G. Peter, Biomaterials 2005, 26, 5414.

[22] X. Lu, Y. Leng, Biomaterials 2004, 25, 1779.

[23] A. R. Boccaccini, J. J. Blaker, V. Maquet, W. Chung, R. Jerome, S. N. Nazhat, J. Mater. Sci. 2006, 41, 3999.

[24] M. Iijima, Y. Moriwaki, J. Cryst. Growth 1998, 194, 125.

[25] X. Lu, Y. Leng, Biomaterials 2005, 26, 1097.

[26] C. Mao, H. Li, F. Cui, C. Ma, Q. Feng, J. Cryst. Growth 1999, 206, 308.

[27] M. Niederberger, H. Colfen, Phys. Chem. Chem. Phys. 2006, 8, 3271.

[28] H. Colfen, S. Mann, Angew. Chem. Int. Ed. 2003, 42, 2350.

[29] P. Saravanapavan, L. L. Hench, J. Biomed. Mater. Res. 2001, 54, 608 .

[30] F. Barrere, P. Layrolle, C. A. Van Blitterswijk, K. De Groot, Bone 1999, 25. 